\title{
The angers of populism: a psychosocial inquiry
}

\author{
Barry Richards
}

\section{Introduction}

Interdisciplinarity

Interdisciplinarity has become a 'new orthodoxy' in academic research, though one that is sometimes more evident in the eager rhetoric of researchers and of university strategic plans rather than in the substance of research. As academics contemplate the escalating complexities of the world, and realise how small is our purchase on it all, it is understandable that we might hope for more power in our efforts - for a great convergence of scholars and perspectives, which would capture the full reality of whatever we are studying. Is the ineffectuality of much social science not simply due to our inability so far to be holistic? If we somehow connected all the disciplinary servers, might we be able to crack the code? With light shining on them from every possible angle, would not even the most intractable of the problems we face yield themselves up for solution?

We should beware 'interdisciplinarity' as a fantasy of full understanding. Yet as an ideal, it is indispensable. It requires humility and open-mindedness amongst researchers. It promises a greater richness of findings, and greater chance of impact or influence because more of the real word has been captured. But we should avoid casual use of the word which ignores the difficulties of actually achieving it. These lie mainly in the meaning of 'inter', as 'between' or 'among'. This implies more than a simple additive relation, for which we could instead use the term 'multidisciplinarity'. It also implies more than the term 'transdisciplinary' might do, depending on how that was defined. The 'trans' prefix suggests a common element, or something laid across disciplines rather than involving the specificities at the core of each one. 'Inter' implies more than commonality or co-operation; it suggests something 'contributing to or derived from two disciplines', as the Oxford English Dictionary ${ }^{1}$ puts it, some combination which depends on, but is qualitatively different from, the content of either taken separately.

One interdisciplinary project which has established itself in British academia in recent decades (and has parallels around the world) is psychosocial studies. In terms of its theoretical base, this is a relatively broad church, and it includes studies of a very wide range of topics in social, cultural and political research. Its unifying feature is in the attempt to develop a kind of binocular vision in which some insights from both psychology and the social sciences are held in mind at the same time. If the integration of the two perspectives is successful, it captures a picture of the object of inquiry which is sharper and richer than that produced through the monocle of any single discipline. Thus psychosocial work differs both from the long-established sub-discipline of psychology called social psychology, insofar as that has been largely concerned with the monocular application of psychological theory to social phenomena, and also from sociological analyses of psychological topics, a diverse tradition stretching from Durkheim through Goffman to Bauman. Both of these approaches can generate or blend into psychosocial work.

\section{Populism}

\footnotetext{
${ }^{1}$ Brown, 1993, p.1393.
} 
In what follows, I offer a psychosocial exploration of populist politics, a phenomenon which demands our attention because it has emerged this century as a dominant force in some countries, and a significant one in many others. The term 'populism' will be taken to refer to a style of political leadership and campaigning which invites its audience to identify itself as a national 'people' whose interests are at risk and must be defended. It champions this 'people' against an elite establishment, and typically it is offered by a charismatic leader who promises a radical renewal of society and culture. In its contemporary 'neo-populist' forms ${ }^{2}$, it is increasingly succeeding in its aim of attracting mass support, though it is often seen as a threat to liberal democracy, and a cause of the polarisation which is occurring in many democratic societies. It has a history reaching back into the centuries, and some links with the fascist movements of the twentieth century, but is not tied to any particular ideology; there are variations in how narrowly the 'people' is defined, and there are populisms of the Left.

Across many international examples, populism as a political narrative usually has two core themes. One is a promise to recover something precious which has been lost - sometimes territory or prosperity, sometimes a culture and the identity it bestows. The other, as captured in the definition of populism given above, is antipathy towards the elite, however 'they' are defined, who are often at least partly blamed for the loss, and who are contrasted with the charismatic populist leader who is, whatever their actual biography, presented as an outsider, untainted by the corruptions of politics. Both these themes are characteristically suffused with anger. It is often this resentful and intemperate anger of populism which seems to underpin it, and which most alarms those who see it as a threat to liberal and cohesive society.

Beginning with some familiar political and social observations and analyses, and noting the gaps in their explanatory power, we will go on to consider how insights from psychoanalytic psychology - in particular those concerning the dynamics of narcissism - can be interwoven with society-level analysis to give a fuller and more complex picture of the drivers of the populist phenomenon. We will focus on the question of where the anger of populism comes from, and what sustains it.

\section{Monocular 1: the societal}

There are several societal-level explanations for populist anger, each focussing on a different type of felt loss - economic, political or cultural - as the source of anger.

\section{The loss of equality}

Equality has never existed and so cannot be lost, but today's growing inequality within societies around the world (which is only partly mitigated by the recent reduction in the global level of absolute poverty) will lead many to feel that something is being lost - a more just society, opportunities for betterment, and a sense of security. Whatever its causes, deep inequality creates large publics despairing of the 'system' and eager for promises of a fairer and more reliable world. The 'austerity' regimes imposed to restabilise national economies and the world system after the crash of 2008 added to this economic driver of polarisation, but material and political divisions within national publics were widening before then, as a consequence of market deregulations begun in the 1980s.

\footnotetext{
${ }^{2}$ See, for example, Sergiu Miscoiu's discussion (2013) of the specific nature of contemporary populisms.
} 
Pankaj Mishra (in his recent book The Age of Anger) has developed a particular version of the thesis that links anger (whether in populism or other political forms) to the ravages of capitalism - both its inequalities, and its deceptive individualism - the combination of promises of individual freedom and fulfilment for all on the one hand with the realities of oppression and limitation on the other. That contradiction produces levels of frustration, envy and rage which, he argues, have been gathering and finding expression throughout the modern era. They have now got to the point where, mobilised in various guises ranging from the Islamic State to neoNazi movements, they are firing 'global civil war'.

\section{The loss of sovereignty}

A second explanation focusses more on the concern with sovereignty and its perceived loss. Nationalist populisms have often been defined in opposition to a historical or current threat of subordination to a domineering external power; recent examples include Greece and Ukraine. This theme has of course been especially important in the Brexit debate, in the argument that the European Union is dominating and shaping British society, in its interfering directives and rules, and its drive towards closer integration. We will return later to the populist element in the Brexit saga.

\section{The loss of identity}

We find a third explanation of populism in the anger which focuses on the dramatic changes in everyday life wrought by globalisation, especially the perceived loss (through dilution or undermining) of the everyday indigenous culture which is for most people an important source and sustenance of their sense of identity and belonging. The most adverse experience of those changes falls to the most impoverished, but the sense of loss and displacement which inevitably accompanies demographic transformations as rapid as those of recent decades is widely felt, and underpins demands for drastic action to restore community. Also, especially in a society seriously short of housing, and with under-resourced educational and health services, any immigration on a mass scale will produce resentment and anxieties about there not being enough to go around. So this explanation easily links up with the first, economic one.

\section{The great betrayal}

The three societal explanations outlined above might seem to offer a complete answer to the question of what causes the anger driving populism. There is some truth in all of them, and in their common-sense psychology which says that adversity which people think could have been avoided will make them angry. People are angry because they are suffering from growing socioeconomic inequality and austerity, because they feel the sovereignty of their national institutions has been destroyed, and/or because they no longer feel at home in the places they or their parents grew up in. However, many angry supporters of populist leaders are well-off, not left behind', and they are not substantially affected either by austerity or by the sense of displacement and dispossession which the less well-off can feel in a rapidly-changing society. Nor would they be able to specify how their freedoms are actually being restricted by supra-national or foreign powers. Similarly, some people with abundant reasons to grieve the losses in question do not feel the anger which might recruit them for a populist cause.

So on closer inspection, these society-level explanations of anger as a response to loss do not generate robustly full explanations of why some people are as angry as they are, in the way that they are. We have noted that loss is one of two core themes in populist narratives that are the gathering points for anger; the other is the blame fixed on the 'establishment' who are held at 
least partly responsible for whatever loss is being felt - the political classes, and the commercial, professional and cultural elites, who have allowed or even caused the situations of economic pressure, political subordination and cultural disinheritance to develop. They are the target of the populists' accusatory rhetoric for their insulated and self-serving ways, and at times their outright corruption.

Again, in some countries at least there may well be a case to make for the populist charge that elites are to blame. There probably is a loosely definable metropolitan segment of the British public which is well represented in the elite worlds of politics, media and business - an upper stratum of David Goodhart's un-rooted cosmopolitan 'Anywheres', including people from old class-based elites. There is a plausible argument that parts of this 'establishment' have been seriously out of touch with the lives and feelings of large sections of the public, and have over several decades contributed to the promotion of economic and social agendas which have damaged the infrastructure of British society and failed to manage the corrosive impacts of globalisation.

But populist rhetoric makes no effort to examine or explain any of this. In its iconography, elites are very poorly defined, and the accusations against them, en bloc, are typically lacking specificity and evidence. One mild but much discussed example of this in the British context was the assertion by leading Conservative politician Michael Gove (himself a fully accredited member of the metropolitan elite) that 'The British people have had enough of experts'.

Moreover, most people have no access to an evidence-based analysis of the existence and influence of elite networks. In repressive regimes, the malignancy of those in power can be a sufficient basis in reality for people to know that the established order is bad one. In liberal democracies, something else (revelations of minor corruptions notwithstanding) is needed for the anger to brew and to find its objects in the particular ways that it does. The hostility to the 'establishment' is visceral and unseeing, and is given its direction almost entirely by headlines, soundbites and constantly recirculated conversational tropes. Complaint and cynicism about multiple unspecified 'thems' and what they do or haven't done are as much a part of everyday British conversation as the weather, and no doubt are equally present in other cultures, but in the relatively polarised condition we find ourselves in now they have a much greater bitterness and urgency - though no more precision.

In recent decades the mainstream media have been important sources of hostility towards the political elite in particular. In 2004 the journalist John Lloyd described the extent to which political journalism was pumping toxic cynicism into the body politic, undermining faith in democratic process. This is actually a case of one section of the elite undermining another, but it does not dim the populists' enthusiasm for their claim that the establishment is united against the people. And since Lloyd's assessment, we have witnessed the increasing scope for social media to intensify suspicion of and contempt for politicians.

There is much evidence from 'media effects' research that public opinions and emotions are substantially shaped by media content. The 'framing' ${ }^{4}$ and agenda-setting functions of media can doubtless amplify feelings of anger amongst the public. Yet although they may to some degree

\footnotetext{
${ }^{3}$ These people contrast with the less educated and less mobile 'Somewheres', the other 'tribe' in the new landscape of British politics, who are still powerfully attached to place and to specific community (Goodhart, 2017).

${ }^{4}$ This term refers to how the choice of words and images in news reports can predispose audiences to think about an issue in a certain way.
} 
shape and focus it, they cannot create it from nothing. As we have seen, experiences of inequality, subordination and disinheritance can be identified as primary sources of anger, albeit not sufficient to explain its particular distribution across the public. When it comes to hostility towards elites, there is rather less in the ordinary person's experience of the real external world to initiate and sustain the anger, which is so intense as to give rise to a language of betrayal, a great betrayal of the people by the elites.

So with abundant help in the mediasphere, populist rhetoric is able to mobilise an anger which, while partly arising in response to the real world, is intensified and taken to boiling point by heat coming from somewhere else. The successes of populist parties and movements rest on convergences of feeling onto their agendas, temporary cajolings of inchoate sounds into simple political harmonies. But the engineering of consent to a political manifesto is not the same as the creation of feeling, ab initio, in the human heart. 'Whipping up' by demagogues and the media can work only if there is something to be whipped up.

And this is where we must turn to political psychology for some further understanding of what is going on. Mishra, for example, does not consider why some people feel the anger and others do not; he writes as if all outside of the elites are gripped by it. The anger towards elites is curated with verve by populist leaders and their commentariat, but how do we explain its depth and origin, given that any rationale it may have in societal reality, though present to some degree, is remote from the experience of most people?

\section{Monocular 2: the psychological}

Here we will focus on one of the internal origins of anger. While an emotion usually needs an external, social context for its articulation and expression, it may not be basically a reaction to the external world, but have its primary source in the inner world of an individual, or in our existential predicament.

\section{The emotional unconscious}

There are two principles to start with, both of which are unpalatable to rationalistic political science. One is that our political views are in large part expressions of our emotional selves. We like or dislike individual politicians, support or reject policies or parties, because of what they mean to us. And while that meaning is shaped partly by attempts we might make to consider arguments and weigh up evidence, it also derives from how the people and the words involved make us feel, beyond any rational calculations. This, by the way, is not a pessimistic view of democracy as a primitive contest of emotions, to be won by the most effective demagogic manipulator, but a hopeful view of it as a potential expression of emotional maturity, of our collective emotional capital.

The second principle, one less familiar to common sense, is that we do not always know what we feel, let alone why we feel it. Despite the repetition, across decades, of attacks on the straw man of early Freudian theory (or rather, on a straw man made of simplistic renderings of Freud), the basic psychoanalytic proposition that there is a powerful unconscious dimension to human subjectivity, that we can be strangers to ourselves, continues to underpin rich developments in the broad field of post-Freudian psychoanalysis. Many people have benefitted personally from the influence of this work in psychotherapy and other professional practices, and it continues to inspire attempts to gain a better understanding of the contemporary world. Here, it poses for us the question of whether there are deeper levels of meaning in the anger driving populisms. 


\section{The Other}

Let us first consider one of the earliest uses of psychoanalysis in the study of politics, developed in mid-twentieth century studies of racism and fascism, and assess its relevance to the topic of populism. As we know all too well, there seems to be in most societies today a standing reserve of sourness and suspiciousness towards strangers which can get pulled into daylight in situations of economic instability or disorienting cultural change. Many observers (not only those with a psychoanalytic perspective) have seen the source of this well of antipathy in an unconscious fear of 'the Other'. Those with a psychoanalytic perspective will go further to suggest how this phenomenon is a part of everyone's psychological development, when as infants (and later) we struggle to establish a sense of selfhood and to come to terms with feelings inside ourselves (particularly of aggression, guilt and helplessness) that at times can be intolerable. The defence of projection enables us to deal with unwanted feelings by experiencing them as present in others, not in ourselves. Hence the 'Other' (whichever group the history and culture of our own group has chosen for this purpose) is the repository of projected parts of how we experience or imagine ourselves - destructive, guilty, demanding, and so on. Like all defences, however, it deals with an internal problem only by creating another: the externalisation of parts of the self creates an Other with whom one cannot live, and who must be avoided, feared or - in the worst case attacked and destroyed in order to defend the self from attack or contamination. Projection of aggression, for example, is the basis of paranoid suspicion of the world.

This analysis is familiar to many scholars of racism since it was first set out by writers of the Frankfurt School in the mid-twentieth century ${ }^{5}$, and it throws important light on racism and fascism. As such it has a crucial part in understanding the ubiquity of the potential for regression into racism of one sort or another that tarnishes a section of most societies: that potential is based on a universal difficulty in the path of psychological development, in the inability of the nascent self to manage its own house. Hopefully most people in most societies will develop enough 'ego strength', in Freudian terminology (or 'emotional capital', to use a more psychosocial term), to manage their inner turbulence in better ways without recourse to massive projection. To what extent that happens, or not, could be established only through a psychosocial analysis of societies case by case. The psychoanalyst Donald Winnicott once guesstimated $^{6}$ that $30-50 \%$ of British people were well enough to make a full contribution to democracy, and it would be an interesting and important task to check this out with an evidencebased profile of our national reserves of emotional capital, though this would not be a simple project.

Without such a profile we should be careful not to apply a diagnosis of massive projection too widely in contemporary Britain and countries like it. A sour or suspicious attitude towards 'immigrants' does not necessarily mean that there is a full-blown paranoid phantasy beneath; there are crucial differences of degree. Populism is not necessarily racist. Though it may often encourage projection-based prejudiced attitudes amongst its supporters, these are not necessarily infused with the degree of hateful rejection which the term racist should imply. Nonetheless, the dynamic of 'Othering' is important to bear in mind as a component in the overall psychology of populism.

\footnotetext{
${ }^{5}$ See, for example, the chapter on Prejudice in the volume introduced by Horkheimer and Adorno.

${ }^{6}$ See his 1950 essay on democracy in the posthumous collection of his papers, $244 \mathrm{ff}$.
} 
Our main purpose here though is to understand the intensity of populist anger towards ruling elites. What, may we ask, is being projected into the images of 'them' which renders them worthy of the contempt and rejection that populism demands?

\section{The imagined freedoms of Brexit}

We will explore this question through a consideration of aspects of the Brexit debate in the UK. Let it be clear at the start of this that there were many reasons why people voted to leave the EU, some of them based on substantive arguments whether economic, political or cultural. The overall result cannot be seen simply as the outcome of a populist campaign. However it is also clear that in the rhetoric of the organised campaigns there was a strong presence of characteristically 'populist' themes - a demand to recover something lost, and an accusation that an elite is to blame for the loss. Also, leaders with a particular type of charisma (the 'popular touch', as possessed by Nigel Farage and Boris Johnson) were prominent in the national debate. We noted earlier the dismissal of expertise; another striking expression of anti-'Establishment' fervour was the Daily Mail front page of 4 November 2016. Under the headline 'Enemies of the people', this carried photographs of three High Court judges who had ruled that Parliament must be consulted before the EU withdrawal process could begin.

The angry preoccupations with the recovery of sovereignty and identity, whatever the substantive arguments involved, have been interwoven with two streams of antipathy: one towards European authorities for their theft of our freedoms, and the other towards our ruling class, our elite 'establishment', for its abandonment (or deliberate destruction) of our independence. Two sets of authority are being rejected here, one for being overbearing, one for weakness (and at times both for corruptness). We are being suffocated by one, neglected by the other, and cheated by both. The desire to Leave, at least in its more polemical and populist expressions, looks very like a desire to escape from authority of any sort. This is why it was such ripe fruit for populist leadership to pick. A hallmark of populism is the claim that it offers a new kind of leadership, one untainted by the flaws and corruptions of all other leaders. It is indeed an offer of ideal leadership, not only in its self-professed moral perfection but also in the way that it apparently offers everything that its public wants. In this, it casts off the unpopular task of deploying authority, in the necessary work of imposing limits and disappointments, and managing disputes in the interests of the whole society. Of course, once elected, populist leaders can turn into highly authoritarian leaders, even while still insisting they bring nothing but milk and honey. But in the purest forms of populism, as found in campaigning propaganda, the populist leader offers the perfect kind of leadership for those who find it hard to bear authority, that is, a leader who offers a world in which, it being ideal, there will be no restrictions or compromises, and so no need for authority.

Our relations with authority are at the centre of our social existence. To state the obvious, group membership of any kind in any context demands acceptance of the authority of the group, however that is represented. Authority, whether as realised in law and the institutions of government or as imagined in the recesses of the human psyche, represents the demands of civilisation, the ineluctable constraints and limits of societal membership. Recognising this is not to see civilisation as a prison of conformity, since individuality can find content and expression only in community. Of course, particular realisations of authority usually - and often foremost represent particular interests within society, and will rightly be met by opposition from any other interest group whose wellbeing is being neglected or attacked by the authorities. But protest and insurgency may also be driven in part by a libertarian objection to authority per se, by what is at psychological root a narcissistic objection to any restraint on the will of the subject. That subject may be an individualised one, where the objection may take the form of demanding, for 
example, freedom of belief, or trade, or expression. It can also be a collectivised one, where the objection to restraint may take the form of a demand that, for example, the preferences of a 'community' must be acceded to, whatever other communities may feel.

This interpretation of protest will be objected to by many people on political grounds, for whom it may only go to show why psychoanalytic ideas should be kept out of politics, and by many psychoanalytic clinicians, for whom interpretations should be offered only in the consulting room. General responses to these important but mistaken objections can be found elsewhere; here we can only acknowledge the controversies, and respond by showing how this approach can throw light on the example of the Brexit debate. This has of course continued since the referendum, and exchanges have become more intense as the difficulties of Leaving have pointed to Remaining as a possible option, and as the Leaving deal negotiated by Theresa May does not satisfy many of the Leavers. As the atmosphere of irresolution and crisis has grown, and Leavers have sensed that their prize might slip away, their polemic has escalated to the point where violence is threatened if Brexit does not happen, not of course by the speaker, who is often an MP, but by a vicarious attribution. Apparently responsible democratic politicians, including the Foreign Secretary Jeremy Hunt (himself a former Remainer) have given dark warnings that a halt in the exit process, and especially an offer of a second referendum, would trigger such deep frustration and anger amongst the public that the nature of the consequential unrest could not be predicted.

These assertions must convey to some in the Leave public that in the possibility of no Brexit there is an injustice to them so massive and humiliating that they are expected make their feelings known on the streets. The columnist Fintan O'Toole has suggested that in some Leave talk the EU appears as 'a masochistic fantasy of an oppression that must be thrown off' ${ }^{7}$. To give the opportunity for second thoughts (either way) and for voting again is described, extraordinarily, as a national betrayal, with that word intended in its full literal meaning. The narrow majority for Leave in the referendum has become a sacramental expression of the will of the British people which is now immutable. A fundamental rupture in the nation is promised if it continues to be subject to an alien authority, or even if we are simply invited to vote again on how we want to relate to that authority. The authority of Europe must be felt as an intrinsically deadly threat for the escape from it to be so necessary and urgent, and therefore for the sanctification of the singular vote which apparently enabled that escape. The willingness of some politicians to contemplate a second referendum is further proof, not that any is needed, of their perfidy.

This position is staked out most clearly by the extreme Brexiteer wing of the Leave movement, but the resilience of public support for Leave, and especially for refusing a second referendum, suggests that it is striking a chord with a wider constituency, that it taps into an underlying and unarticulated resistance to political leadership of any sort, save that which promises to meet in full the citizen's desire. I am suggesting therefore that a hidden strand of Brexit lies in the narcissistic intolerance of authority per se. That intolerance, and the iconoclastic and insurrectional impulses to which it gives rise, are usually accompanied by a thirst for visions of rebirth into an untrammelled freedom in the world. In this phantasy of subjugation and release from it, the imagined freedom is the prize for destroying the threat of catastrophe, of continued subjugation to the EU.

Why this different spelling of phantasy? We are dealing here with what psychoanalysts call phantasy, that is, an unconscious template for conscious experience, as distinct from fantasy as the

\footnotetext{
${ }^{7}$ His article '..' in .... summarises an argument developed in his book (O’Toole, 2018).
} 
conscious product of the imagination. Both may be organised around the same scenario (here, oppression and liberation), but the unconscious phantasy is the driving force which can influence experience in such a way that situations in the world are perceived as enactments of the phantasy. ${ }^{8}$ In the case of populist anger, the phantasy is two-fold. First, there is massive humiliation by cruel and exploitative authority figures, often in collusion with other authority figures who should instead have been protective and prevented the humiliation. Then there is a redemptive passage in which the subject somehow defeats all the forces of oppression, which leads to the second tableau, the blissful restoration of pleasure and dignity. This is the underlying structure of experience, a narcissistic phantasy of recovering a lost state of complete freedom and satisfaction, in which there is no authority to challenge the omnipotent self.

Narcissistic demands for absolute freedom are not spontaneous emissions of built-in grandiosity; they are defences, built up in emotional development when the world and the people in it do not seem to offer us a safe and dependable enough place for us to allow ourselves to be anchored in it, and to have connections which involve dependency on others. For this essentially fearful state of mind, dependency involves a lack of safety and of dignity. The world is unsafe, because we cannot trust it to look after us, and humiliating, because we are dependent on it. The narcissistic phantasy of self-sufficiency enables the self-deceiving subject to transcend all that anxiety and pain.

When deployed in the service of populism, this defence provides the psychic driver for the rejection of the authority of any actually-existing government. Authority is the representative of the ultimate real other, the inescapable otherness of others and their needs, and so constitutes an existential threat to the narcissistic self.

\section{Binocular: the psychosocial}

\section{Confronting the narcissistic self}

It can be a little harder to establish the credibility of the psychological analysis outlined above than that of the familiar societal analyses set out previously. The concept of unconscious phantasy sits uneasily in the positivistic milieux of both social science and common sense. But if sceptical readers will suspend disbelief a while, we can consider whether we can now proceed to a further discussion of anger and populism in which some capacity for binocular, psychosocial understanding may emerge.

Our task has been to understand the sources of the anger on which the rise of populist leadership depends, and I have argued that these sources include not only much-discussed features of the state of the world (which we may reduce to two, inequalities and globalisation) but also a tendency built-in to the human psyche to chafe at being governed. Populism is a catalyst which tunes into, and amplifies, the phantasy of humiliation at being governed that sits in the psyches of us all, and hooks it up with real issues, bringing the regressive craving for absolute freedom into the service of 'independence' movements linked to anxieties about material security and cultural identity. So deep and real though the societal issues are, there is another layer of psychic recalcitrance when it comes to any issues around subordination and the

\footnotetext{
${ }^{8}$ There are many places in the psychoanalytic literature where the concept of unconscious phantasy is explained. It is closely linked to the 'relational' turn in psychoanalysis, that is the shift from seeing human needs fundamentally in terms of relationships rather than drives. Two classic texts on this turn are Greenberg \& Mitchell, and Guntrip.
} 
basic legitimacy of any particular authority, a layer which is possibly beyond politics, since it is anti-political in a very deep way. Politics is about authority, and here we have the refusal of all authority.

We have taken some illustrations from the complex dynamics around Brexit. At the levels of conscious experience and of sociological analysis, Brexit is heavily about immigration and cultural identity. The anxieties at work here could in themselves have been potentially manageable at European level if the architects and managers of the Union had a creative strategy for nurturing national identities within a framework of political affiliation and economic integration. The absence of such a strategy may have been sufficient in itself to trigger a movement for exit, but the anxieties have also become intertwined with an unconscious dynamic involving narcissistic visions of independence and freedom, and so for a narrow majority of the British public in 2016 were tied into the demand for exit.

So, while it is bad enough to contemplate populism as a threat to liberal democracy ${ }^{9}$, it is also part of what may be an even more tectonic movement: an increment in the human difficulty in accepting human society and its necessary authorities. This possibility adds a depth-psychological dimension to Mishra's thesis about the role of individualism and its frustrations in the genesis of populist anger. That thesis would then need reformulating in a psychosocial mode as follows. In the global development of modernity over more than two centuries, a primitive and diffuse anger has been building up in particular segments of most national publics, partly as a direct result of the sociological conditions described in various ways by Mishra and many writers on populism, and partly as a product of how these conditions have somehow interacted with the intrinsically narcissistic tendencies of the human mind, with the result of intensifying the narcissistic complex. This latter development takes many diverse forms and feeds into or influences a wide range of socio-cultural and political phenomena, including ideologies and cultures of individualism (within which we can include neo-liberalism) but also including a major strand of consumer culture, aspects of 'identity politics', and the milieu of 'post-truth'. On this view, populist anger is not a distinctive or stand-alone phenomenon, but is part of a much wider development, which includes many other expressions of the grandiose self refusing the authority of the societal other and its expression in the key institutions of society.

Hopefully a measure of binocularity is beginning to emerge in this formulation, but there is a major step which needs taking towards a more deeply psychosocial approach. This step starts from the suggestion above that the socio-historical context might somehow shape the mind, and facilitate the development or strengthening of some psychic organisations or complexes over others. This idea has a long history, going back at least to Erich Fromm's conception of 'social character $^{10}$, a modal form of self which reflects the demands of a broad type of society. Here, the hypothesis would be that material, cultural, institutional and ideological aspects of modernity have favoured the development of narcissistic states of mind. This is, to say the least, an ambitious hypothesis, far too broad to be of much use in itself without much closer specification, but it may serve here to help us model the next step in developing binocular vision.

\section{Early development: the psycho-social bridge}

There is a link missing in our discussion so far. We have talked about broad features of the external world of society and culture, and similarly about configurations of the internal world of

\footnotetext{
${ }^{9}$ As proposed by, for example, Richard Eatwell and Matthew Goodwin in their 2018 book on populism.

${ }^{10}$ This concept runs through many of Fromm's rich writings on psychoanalysis and society. It is laid out quite fully in the Appendix to his book The Fear of Freedom.
} 
phantasies and defences. While certain kinds of experience in adult life may impact deeply on the internal world, the major configurations are established very early on, so in suggesting that there is a historical trajectory of increase in narcissistic traits we are implying that there has been some ongoing change in patterns of family life and in the exchanges between caregivers and infants from which the individual character with its particular resources and defences emerges.

There was one very substantial, and for a while very influential, attempt to do just that in relation to the increasing prominence of narcissistic disorders in the post-WW2 period. The historian Christopher Lasch argued in 1978 that the undermining of parental authority by consumer culture, by intrusive professionals and by authoritarian welfarism was impairing emotional development, because strong ego and identity development depends on confrontations with authority, and their resolution, in the context of secure and loving relationships. The weakening of parental roles and confidence was damaging that process and thereby resulting in more people turning to narcissistic defences against the inner weakness of ego and identity, and against the sense of vulnerability. This process will impact to different degrees and in different ways on different families, depending on their situations, their internal dynamics and their reserves of emotional capital. This is why some people seem to embody the malaise of the time much more than others, and some not at all.

In the decades since that diagnosis, the world has become more deeply marketised, state/society relations have changed, and patterns of psychological disorder and breakdown have been changing, so the diagnosis would need revising for the present. Nonetheless, this example shows how sociological and psychological perspectives can be integrated, and the dynamic exchanges between them seen as part of a constant interactive process. Certain changes in the external world of society lead to deep changes in internal psychology, which (after a generational time lag) then become manifest in the culture and drive further social changes in society, which may either reinforce or change again the by-then-established patterns of psychological functioning.

One concept which may be particularly helpful in linking outer and inner worlds is that of trust. The sociologist Anthony Giddens, some of whose work touches on the psychosocial, is one to have set out the central role of trust in modern societies ${ }^{11}$. We need to trust in money, in the law and its application, in a host of institutions and professions, in our food, etc., as well as in people generally. It is clear that trust is particularly important in liberal democracies, which would not function politically if there were no trust in their processes and personnel. The foundations of trust, as Giddens notes, are in the earliest phase of psychological development, in the establishment of what Eric Erikson in 1950 famously called 'basic trust'. I have suggested that part of the anger underlying the current successes of populism is fuelled by a narcissistic rage that in turn is a product of an erosion of basic trust. A Lasch-style analysis of narcissism would suggest that this reduction in our emotional capital is increasing over time. Another possibility is that there may not be this deterioration in our emotional development as individuals, but rather an increase in what the political and cultural conditions we have created now ask of us. Liberal welfare democracies in the age of globalisation are perhaps the most demanding form of society in what they ask, emotionally, of their citizens - capacities for empathy, identification with the common weal, generosity, and the tolerance of uncertainty and complexity. As such they are most likely to touch on and irritate that part of the collective psyche which recoils from any requirement to give up a measure of our phantasied freedom in the service of the whole.

Are we then changing for the worse, and thus becoming more likely to fall for aspiring leaders who profess that the only task of leadership is to free the people from leaders? Or are these

${ }^{11}$ In his book on the nature of modernity - Giddens, 1990. 
would-be governors, who apparently hate governance, benefitting from excessive demands placed on our psyches by systems embodying aspirations which currently extend beyond our collective capabilities? These and other questions about populism need the continued attention of interdisciplinary inquiry - especially in its psychosocial form.

\section{References}

Brown, L., ed. (1993) The New Shorter Oxford English Dictionary. Oxford: Oxford University Press. Eatwell, R. \& Goodwin, M. (2018) National Populism: The Revolt Against Liberal Democracy. London: Pelican.

Erikson, E. (1950) Childhood and Society. Harmondsworth: Penguin, 1965.

Fromm, E. (1942) The Fear of Freedom. London: Ark Paperbacks, 1984.

Giddens, A. (1990) The Consequences of Modernity. Cambridge: Polity.

Goodhart, D. (2017) The Road to Somewhere. London: Penguin.

Greenberg, J. \& Mitchell, S. (1983) Object Relations in Psychoanalytic Theory. Cambridge, Mass.:

Harvard University Press.

Guntrip, H. (1971) Psychoanalytic Theory, Therapy and the Self. London: Karnac, 1977.

Horkheimer, M. \& Adorno, T. (1956) Aspects of Sociology. London: Heinemann, 1973.

Lasch, C. (1978) The Culture of Narcissism. New York: Norton.

Lloyd, J. (2004) What the Media are Doing to our Politics. London: Constable.

Miscoiu, S. (2013) From populism to neo-populism? Empirical guidelines for a conceptual delineation. In Soare, S., Miscoiu, S. \& Ghergina, S., eds., Contemporary Populism: A Controversial Concept and its Diverse Forms. Newcastle: Cambridge Scholars Publishing.

Mishra, P. (2017) Age of Anger. A History of the Present. London: Penguin.

O’Toole, F. (2018)

Winnicott, D. (1950) Some thoughts on the meaning of the word 'democracy'. In Home Is Where We Start From, 239-259. London: Penguin, 1986. 